\title{
ANÁLISE DA FUNÇÃO DO TRADE MARKETING: ESTUDO DE CASO EM UMA EMPRESA MULTINACIONAL DE BEBIDAS NA CIDADE DE RIBEIRÃO PRETO - SP
}

\section{RESUMO}

Nesse estudo, por meio de um estudo de caso desenvolvido junto a uma empresa multinacional no setor de bebidas instalada no interior do Estado de São Paulo, verificou as funções e operações do Trade Marketing. Para tanto, foram entrevistados os principais gestores de departamentos do distribuidor (Trade Marketing e Vendas), e do varejo supermercadista (Trade Marketing e Gestores de Categoria). Para interpretação das entrevistas foi utilizado a técnica de análise de conteúdo. Os principais resultados apontam que os membros do canal, adotam o Trade Marketing na estrutura de suas empresas, muito embora, de forma diferentes, divergindo de certa maneira do verificado na literatura, pois, no distribuidor, o departamento foi criado para dar suporte para a área de vendas, enquanto que na rede varejista ele foi criado para obtenção de um sortimento mais adequado e uma melhor dedicação da empresa, além de melhorar o relacionamento para com o distribuidor e capacidade de análise de mercado. Desse contexto, verifica-se a maior contribuição desse estudo, pois, ao divergir da literatura, apresenta uma adaptação no modelo de negócio pelo varejista. Concluímos em indicar essa verificação para pesquisas futuras.

Palavra-Chave: Trade Marketing, Setor de bebidas, Distribuidor, Varejista.

\author{
${ }^{1}$ Renata Deliberali \\ ${ }^{2}$ Paulo Sérgio Miranda Mendonça \\ ${ }^{3}$ Carlos Alberto Xavier do Nascimento
}

DOI: $\underline{\text { http://dx.doi.org/10.26668/businessreview/2017.v2i1.42 }}$

\section{FUNCTION ANALYSIS OF TRADE MARKETING: A CASE STUDY IN A MULTINATIONAL BEVERAGE COMPANY IN THE CITY OF RIBEIRÃO PRETO - SP}

\begin{abstract}
In this study, through a case study developed with a multinational company in a beverage industry installed in the State of São Paulo, it was verified the functions and operations of Trade Marketing. For this, we interviewed key managers of distributor departments (Trade Marketing and Sales), and of retail supermarket (Trade Marketing and Category Managers). For interpretation of the interviews was used the technique of content analysis. The main results show that the channel members, adopt the Trade Marketing in the structure of their companies, although in different forms, differing in a way found in the literature, because the distributor, the department was created to give support to the sales, while the retailer it was created to obtain a better assortment and better dedication of the company, in addition to improving the relationship to the distributor and market analysis capabilities. In this context, there is
\end{abstract}

\footnotetext{
${ }^{1}$ Administração pela Universidade de São Paulo - USP (Brasil). E-mail: renatadeliberali@gmail.com

${ }^{2}$ Administraçao pela Faculdade de Economia, Administração e Contabilidade de Ribeirão Preto da Universidade de São Paulo (Brasil). E-mail: paulomiranda@usp.br

${ }^{3}$ Administração pela Universidade Federal de Goiás - UFGO, Goiás (Brasil).

E-mail: carlosnascimento@ rocketmail.com
} 
the greatest contribution of this study, therefore, to diverge from the literature, presents an adaptation of business by the retail model. We concluded to indicate that check for future research

Keyboards: Trade Marketing, Sector drinks, Distributor, Retailer.

\section{INTRODUÇÃO}

Tem ganho destaque estudos sobre Trade Marketing e suas implicações nos negócios empresariais e, no presente estudo, consideramos o cenário brasileiro a partir da década de 1970 em que todos os grandes fabricantes eram empresas nacionais e com atuação regional. Eram também negócios familiares, gerenciados pelos proprietários, não havendo contratação de equipes especializadas em gestão, conforme afirmam (Serralvo, Motta \& Santos (2008). As grandes indústrias utilizavam seu poder de barganha para intimidarem os pequenos varejistas a fim de atingirem seus objetivos. Contudo, ainda na mesma década de 1970, o cenário que por influências advindas dos efeitos da globalização juntamente com a consolidação supermercadista começa a modificar, os varejistas passam a ganhar força a ponto de intervir na relação com as indústrias fornecedoras que, ao perderem rentabilidade se veem obrigadas a trabalhar com melhores preços e serviços. A partir de então, emergiu a necessidade de mudança estratégica, pois, apenas reduzir custos não mais era suficiente para obtenção de resultados como antes ocorria. As indústrias passaram a desenvolver canais que facilitassem o relacionamento entre os varejistas a fim de que os produtos e serviços fossem entregues com valor para o consumidor final. É nesse cenário que na década de 1980, algumas empresas desenvolveram o Trade Marketing conforme apontam (Cônsoli \& D`Andrea, 2010, p. 33), tornando o assunto relevante tanto para estratégica de negócios das empresas como para academia, pois, abarca conceitos advindos do marketing e insere-se definitivamente como departamento na estrutura empresarial.

Buscar entender o contexto em que a área do Trade Marketing pode colaborar para com as empresas se torna então uma questão emergente. O tema Trade Marketing que embora recente e ainda com poucos estudos (Barros, 2015; Cônsoli; D’Andrea, 2010), tem colaborado na compreensão e articulação do relacionamento entre os membros do canal de marketing até os consumidores finais. Da revisão de literatura encontramos estudos que abarcam o tema em relação ao varejo, alta competição entre os fabricantes, relacionamento entre produtores e distribuidores e, atuação dos membros nos canais (Randall,1994; Dupuis, Tissier-Desbordes, 1994; 1996; Mentzer, Min e Zacharia, 2000; Da Costa, 2004; Arbache, 2006; Alvarez, 2008; Serralvo, Motta e Santos 2008; Silva Neto, 2009; Cônsoli; D’Andréa 2010; Dewsnap e Jobber, 2009; Chung, 2012; Almeida, 2012), bem como estudos sobre a verificação da estrutura organizacional, devidamente apontados por (Serralvo, Motta \& Santos, 2008).

A partir dos estudos, verificamos que fora criado departamento próprio na área de Trade Marketing e, conforme (Cônsoli \& D’Andrea (2010), três fatores colaboraram para o surgimento desse departamento: i) o ponto de venda restrito ao número de marca, ii) um comprador bastante estimulado e confuso e iii) os objetivos divergentes entre os varejistas. Os autores sustentam que o principal objetivo do departamento é tentar reduzir os conflitos que existem nos canais de distribuição a ponto deles inexistirem e, portanto, passa a ser um desafio entender a funcionalidade da função do Trade Marketing. Por fim, enfatizam não haver apenas uma definição do termo, principalmente pelo fato de ser algo embrionário com relação a investigação, desenvolvimento e prática empresarial recente no Brasil.

Diante o exposto, o presente trabalho tem questão de pesquisa analisar a função e como opera o profissional de Trade Marketing no setor de bebidas, em específico, numa empresa multinacional distribuidora de refrigerantes e cervejas, instalada na cidade de Ribeirão Preto/SP.

Para atender ao objetivo de estudo, adotamos como método o estudo de caso, como indicado por (Yin 2010). Cabe enfatizar que embora de único caso, realizamos entrevistas com vários envolvidos no canal de distribuição, dentre eles gestores da área de Trade marketing do distribuidor e do varejista, além de funcionários compradores do varejo supermercadista. A partir das entrevistas feitas com gestores e varejistas, foi aplicado a técnica de análise de conteúdo, conforme indica (Bardin 2011).

Mediante análise dos resultados, verificamos existir uma certa, mas não total divergência entre a prática e a teoria. O departamento de Trade Marketing na empresa de bebidas foi criado para dar suporte para a área de vendas, enquanto que na rede varejista ele foi criado para obtenção de um sortimento 
mais adequado e uma melhor dedicação da empresa, além de poder ter uma outra forma de relacionamento com o distribuidor e análise de mercado. Muito embora, algumas funções possam diferir, quando de ações no ponto de venda, são iguais.

\section{REVISÃO DE LITERATURA 2.1 Trade Marketing}

A presente seção apresenta os conceitos de Trade Marketing encontrados na literatura. Verificamos que os conceitos apresentados integram entre si. Embora a literatura sobre o tema ainda é escassa em relação aos demais temas de marketing, é possível apresentar contexto coerente e sólido na construção do presente estudo.

Quando verificado o trabalho de (Arbache, 2006, p. 136,) obtém-se que Trade Marketing "é a ciência que investiga e discute o desenvolvimento das relações entre fabricantes e canais de venda, pelo entendimento da relação entre as marcas, ponto de venda e consumidores"

No estudo de (Serralvo, Motta \& Santos, 2008, p. 48), define e correlaciona a área de Trade Marketing como responsável em ajustar as demandas geradas nos canais de vendas e distribuição, pois, para eles, o "Trade Marketing opera no sentido de adequar a estratégia, a estrutura e a operação da companhia à dinâmica dos canais de distribuição, com o objetivo de atender melhor e mais rentavelmente seus clientes e, por seu intermédio, os consumidores".

Para (Alvarez, 2008) o Trade Marketing está relacionado ao apoio e orientação das ações de Marketing e Vendas para conseguirem atender as necessidades do consumidor final e do varejista. Para o autor, a empresa passa adotar como filosofia de negócios entendendo que o foco para o consumidor final deve ser realizado no ponto de venda com a ajuda dos departamentos de Marketing e Vendas e com o cliente varejista para que a atratividade seja grande e com isso aumentem as vendas e a rentabilidade. Ainda segundo o autor, a evolução da área de Trade Marketing contempla 5 fases: I) fase de Vendas, II) Fase de Marketing, III) Fase de Cliente, IV) Fase do Resultado Financeiro e V) Fase de Desenvolvimento de Negócios.

Para (Cônsoli \& D’Andréa, 2010), o Trade Marketing utiliza de alguns princípios do Marketing para elaborar estratégias de distribuição para produtos ou serviços. Para tanto, serve-se de técnicas de incentivos e ações promocionais que venham adequar-se tanto ao distribuidor, como também ao consumidor final. Nessa linha, outros autores foram encontrados como (Dewsnap \& Jobber, 2009; Dupuis \& Tissier-Desbordes, 1994, 1996; Mentzer, Min \& Zacharia, 2000).

Segundo menciona (Randall, 1994), a consolidação do poder do varejo, fazendo com que os fabricantes aumentassem seus esforços na construção e consolidação de marcar fortes, mudando suas estratégias e estruturas para poder se adaptar à nova realidade e construir parcerias no canal distribuidor, em especial, os varejistas.

A Associação Brasileira de Anunciantes (2012), em conformidade com o proposto por (Serralvo, Motta \& Santos, 2008), quanto à adequação do Trade Marketing à dinâmica do canal, enfatizam que "importante característica do Trade Marketing é a criação de um relacionamento entre fornecedor e cliente, que vai além da negociação. A prioridade da área não são as questões comerciais e sim o planejamento estratégico de médio e longo prazo"

Dado as definições mencionadas, é importante enfatizar que o Trade Marketing passa a ser um departamento próprio na estrutura das empresas. Contudo, a literatura não identifica com exatidão quando nem onde surgiram os primeiros departamentos. No estudo de (Cônsoli \& D`Andrea (2010, p. 33) verificamos que os primeiros departamentos tiveram origem na Europa, na década de 1980.

Para Alvarez (2008), o departamento de Trade Marketing tem como principal objetivo, fornecer suporte às atividades das áreas de marketing e vendas, satisfazendo assim as necessidades de intermediários e clientes finais, além de aumentar o giro de produtos no ponto de venda.

No Brasil, segundo apontado por Barros (2015, p. 43), o primeiro departamento de Trade Marketing que se tem menção fora criado pela Kolynos ${ }^{\circledR}$ em 1995 e, segundo apontado por (Serralvo, Motta \& Santos, 2008), surgiu como consequências de sete mudanças verificadas no varejo, sendo elas: globalização, consolidação das redes supermercadistas, surgimento de novos formatos varejistas, aparecimento de marcas próprias (e proliferação das marcas em geral), constituição de centrais de negócios por parte de pequenos varejistas, concorrência entre varejistas de configurações distintas e 
implementação do varejo on-line. Para tanto, ele pode adequar a parte estratégica, a estrutura e a operação dos canais.

Segundo (Randall, 1994, p.112), a adequação na estrutura das empresas deu-se pela necessidade de ajuste ao novo ambiente de negócios, advindos da relação de poder entre os membros do canal, quais sejam, os fabricantes e principalmente os varejistas.

Conceitos importantes extraídos da literatura, e com aderência ao tema Trade Marketing também colaboram na construção teórica desse estudo, autores como (Kotler \& Keller, 2012; Coughlan et al, 2011) referentes a canais distribuidores, (Blessa, 2010), Merchandising, (Alvarez, 2008; Serralvo, Motta \& Santos, 2008; Cônsoli \& D’Andréa, 2010), sobre Funções do Trade Marketing, e por fim, Confiança (Coughlan et al, 2011).

A síntese de artigos encontrados aos quais colaboram diretamente ao objeto desse estudo são apresentados na figura 1 .

\begin{tabular}{|c|c|c|c|}
\hline Ano & $\begin{array}{c}\text { Autor } \\
\text { (es) }\end{array}$ & Verificação & Resultados \\
\hline 2004 & $\begin{array}{c}\mathrm{Da} \\
\text { Costa }\end{array}$ & $\begin{array}{l}\text { Empresa } \\
\text { avícola no } \\
\text { Ceará }\end{array}$ & $\begin{array}{l}\text { Apresentou um mix de Trade Marketing que combina ações e ferramentas que } \\
\text { são aplicadas nas empresas para dar suporte ao departamento. O mix é } \\
\text { composto pelos elementos promoção, vendas (com a substituição dos } \\
\text { vendedores por funcionários do Trade Marketing nos principais clientes que } \\
\text { tem uma alta participação no faturamento); considera também que possa } \\
\text { existir alguma confusão com os temas de Trade Marketing e as vendas } \\
\text { tradicionais }\end{array}$ \\
\hline 2009 & $\begin{array}{l}\text { Silva } \\
\text { Neto }\end{array}$ & $\begin{array}{l}\text { Empresas de } \\
\text { bens de } \\
\text { consumo no } \\
\text { Brasil }\end{array}$ & $\begin{array}{l}\text { Buscou verificar quais os fatores contribuem e quais dificultam a atuação do } \\
\text { Trade Marketing nas empresas de bens de consumo no Brasil. Considerou que } \\
\text { existem dois tipos de variáveis, as principais (organizacionais dependentes e } \\
\text { independentes) e as secundárias que são as externas. }\end{array}$ \\
\hline 2012 & Chung & $\begin{array}{l}\text { Oportunismo } \\
\text { e Poder - } \\
\text { Pequenos } \\
\text { Varejistas }\end{array}$ & $\begin{array}{l}\text { Discussão entre oportunismo e interesse próprio dos fabricantes sobre os } \\
\text { pequenos varejistas. Os fabricantes têm maior poder sobre os pequenos } \\
\text { varejistas por terem menos recursos que os outros competidores para poderem } \\
\text { fazer alterações nos negócios, isso faz com que eles tenham maior tolerância } \\
\text { para o oportunismo. }\end{array}$ \\
\hline 2012 & $\begin{array}{c}\text { Almei } \\
\text { da }\end{array}$ & $\begin{array}{c}\text { Estrutura } \\
\text { organizacion } \\
\text { al e as } \\
\text { atribuições } \\
\text { do Trade } \\
\text { Marketing } \\
\text { no setor de } \\
\text { lojas de } \\
\text { conveniência }\end{array}$ & $\begin{array}{l}\text { Utilizou o método descritivo e exploratório através de estudo de caso } \\
\text { múltiplo. Dos resultados pode verificar que as lojas de conveniência têm } \\
\text { potencial para serem parceiros cada vez mais fortes nas ações do Trade } \\
\text { Marketing. Além disso, foi constatado que alguns fatores como presença de } \\
\text { informação de vendas, alta frequência semanal de compras e capilaridade de } \\
\text { ação geográfica fazem com que a indústria veja o Trade Marketing de forma } \\
\text { positiva. Foi verificado também que área de Trade Marketing não garante que } \\
\text { haverá colaboração entre os fabricantes e varejistas das lojas de conveniência. }\end{array}$ \\
\hline
\end{tabular}

Figura 1 - Principais pesquisas/autores/resultados. Fonte: elaborado pelos autores (2016).

A partir do contextualizado na seção e em especial ao apresentado na figura 1, compreende-se os principais resultados sobre o tema Trade Marketing extraídos da literatura. Desses resultados além de apresentar o tema, foram utilizados para o desenvolvimento das entrevistas desse trabalho, em especial: presença e informação de vendas (Almeida, 2012); sistemas de treinamento, sistemas de informação e processos (Silva Neto, 2009); oportunismo e poder (Chung, 2012).

\subsection{Setor de Bebidas}

No presente estudo, serão analisados somente refrigerante e cerveja, afinal, de acordo com informações coletadas com os entrevistados, no segmento de refrigerantes, um de seus guaranás é líder histórico no segmento no país e no segmento de cervejas, a empresa ocupa a $4^{a}$ posição dentre as maiores cervejarias do mundo, inclusive uma de suas marcas é a $3^{\mathrm{a}}$ mais consumida mundialmente.

Quanto ao segmento de refrigerantes, de acordo com a AFREBRAS (2016), esse setor teve início no ano de 1904, quando a primeira indústria foi instalada no país. O mercado de refrigerantes é dividido 
em: (I) grandes corporações multinacionais: é formado pela Coca-Cola Brasil, Ambev e Brasil Kirin (todas possuem grande capital com participação internacional); (II) grandes empresas: é um grupo de 15 empresas que não estão vinculadas a nenhum grupo de caráter multinacional; (III) pequenas empresas regionais: formam um grupo de 180 empresas distribuídas por todo o país. A participação de mercado de cada grupo está na seguinte proporção: Brasil Lirin com 6\%, Ambev com 18\%, Coca Cola com $60 \%$ e os outras $16 \%$.

Ainda segundo a AFREBRAS (2016), tanto a produção de refrigerantes como a de cervejas é controlada pelo Sistema de Controle de Produção de Bebidas - SICOBE.

Quanto a indústria cervejeira, segundo a AFREBRAS (2016), esse segmento atraiu interesses de grandes empresas internacionais, devido ao bom desempenho que passava a economia brasileira. As multinacionais entraram primeiramente através de associações com empresas que já estavam no país. Em um segundo momento, a indústria cervejeira passou a realizar uma série de fusões e aquisições, resultando no aumento na quantidade de indústrias no setor. Por outro lado, por consequência das fusões e aquisições nesse setor, acabou por provocar concentração no setor, pois, conforme verificado, a empresa líder detém aproximados $70 \%$ do mercado.

\section{MÉTODO}

Para a realização desse trabalho e, dado a pouca existência de estudos no tema utilizamos o método de estudo de caso, conforme indicado por (Yin, 2010), inclusive com elaboração de protocolo de pesquisa conforme indicado pelo autor. Para tanto buscamos encontrar mais informações decorrentes da prática. $\mathrm{O}$ estudo foi realizado em uma empresa multinacional distribuidora de refrigerantes e cervejas na cidade de Ribeirão Preto-SP.

Dado a característica desse estudo, de foco qualitativo, utilizamos análise teórica extraída da literatura em livros e artigos nas principais bases, como Google Acadêmico, Periódico Capes, Web of Science, Scopus e Teses USP, coletando conceitos importantes aos quais subsidiaram no procedimento de entrevistas.

Realizamos entrevistas com 05 (cinco) profissionais atuantes e envolvidos na área de Trade Marketing do distribuidor e também do varejista. O varejista é proprietário de uma rede (supermercados), com 33 (trina e três) lojas no interior do Estado de São Paulo e, as entrevistas ocorreram na seguinte proporção: um gestor de Trade marketing e um gestor de vendas do distribuidor, um gestor de Trade Marketing da rede varejista e dois gestores da categoria (compradores) da rede varejista.

A opção de entrevistar na rede varejista (supermercados) se deu por dois motivos. Em primeiro lugar pela importância desse canal de distribuição - final, conforme caracterizou-se na revisão de literatura e em segundo lugar pela verificação de sua organização na estrutura organizacional em que também é encontrado um departamento de Trade Marketing.

As entrevistas dos gestores do distribuidor foram divididas em três grandes grupos de perguntas, o primeiro relaciona-se com a função do departamento na empresa, o segundo está relacionado com a operação/funcionamento do Trade Marketing e o terceiro com o relacionamento para ser verificado como é feito o relacionamento da empresa com os varejistas.

Da mesma forma que a entrevista anterior, a dos varejistas também foi dividida nos três grupos. $\mathrm{O}$ de função, relacionado com a função do departamento de Trade Marketing, o de operação que tem relação a como é operado e relacionamento que tem a intenção de verificar como é o relacionamento entre varejista e fabricante. Essa entrevista foi aplicada a dois compradores do supermercado, atualmente chamados de gestores de categoria. A partir das entrevistas feitas, foi aplicado a técnica de análise de conteúdo (Bardin, 2011).

Por fim, vale mencionar que dos resultados extraídos nas entrevistas, será possível além de atender ao objetivo desse estudo, verificando a relação entre teoria e prática sobre o tema de estudo, obter um "retrato" atualizado nas especificidades desse caso, que por se tratar de uma multinacional, implica em sinalizar forte motivação de estudo. 


\section{RESULTADOS}

Conforme mencionado, as entrevistas foram aplicadas com gestores da área de Marketing, Trade Marketing, Merchandising e Vendas da empresa de bebidas multinacional na cidade de Ribeirão Preto. Ao entrar em contato com a empresa para a realização das entrevistas, o gerente de Trade Marketing informou que eles nunca falam em Marketing, sempre em Trade Marketing e acredita que a divisão entre os dois setores praticamente não exista. No entanto, mencionou que as atividades relacionadas ao que na teoria chamamos de departamento de Marketing e Merchandising não são executadas em Ribeirão Preto e estão relacionadas à inovação. Sendo assim, foram aplicadas entrevistas com gestores de Trade Marketing e Vendas. Dos resultados apurados, é apresentado na figura 2 um quadro comparativo entre distribuidor e varejista com principais achados da entrevista.

Figura 2 - Apresentação dos principais conceitos e variáveis.

\begin{tabular}{|c|c|c|}
\hline $\begin{array}{c}\text { Pontos } \\
\text { principais/ } \\
\text { Variáveis } \\
\end{array}$ & Empresa de Bebidas & Varejista \\
\hline $\begin{array}{l}\text { Criação do } \\
\text { Trade } \\
\text { Marketing }\end{array}$ & $\begin{array}{l}\text { Criado com a finalidade de dar suporte para } \\
\text { a área de Vendas }\end{array}$ & $\begin{array}{l}\text { Antes de existir o Trade Marketing tudo era } \\
\text { responsabilidade do Marketing. A empresa era } \\
\text { menor. Com o crescimento da mesma, foi } \\
\text { necessário a criação do Trade Marketing. Além } \\
\text { disso, foi criado para dedicar mais, para ter } \\
\text { sortimento adequado, verificar o que o mercado } \\
\text { está trabalhando e também para se relacionar } \\
\text { com o fornecedor. }\end{array}$ \\
\hline $\begin{array}{l}\text { Estrutura do } \\
\text { Trade } \\
\text { Marketing }\end{array}$ & $\begin{array}{l}\text { Existem três grandes subdivisões: área de } \\
\text { execução, a área de VIP e connections. A } \\
\text { hierarquia dos cargos é, em ordem } \\
\text { decrescente, o vice-presidente, gerente de } \\
\text { marketing regional, gerente de marketing- } \\
\text { execução e supervisores. }\end{array}$ & $\begin{array}{l}\text { A área continua sendo do Marketing, mas } \\
\text { atualmente é mais voltada para o comercial, } \\
\text { como ponto de loja e layout. O cargo mais alto } \\
\text { é o gerente de Trade Marketing, abaixo vem o } \\
\text { coordenador e os assistentes em seguida. }\end{array}$ \\
\hline Treinamentos & $\begin{array}{l}\text { É feito praticamente semanalmente, mas é } \\
\text { um treinamento que toda a área comercial } \\
\text { tem. }\end{array}$ & $\begin{array}{l}\text { Os treinamentos são feitos pelos antigos } \\
\text { funcionários para os novos. Conforme a } \\
\text { empresa vai necessitando de mais funcionários } \\
\text { os de loja são remanejados e são treinados. Caso } \\
\text { apareça uma ferramenta nova, ela é apresentada } \\
\text { aos integrantes do departamento. }\end{array}$ \\
\hline $\begin{array}{l}\text { Habilidades } \\
\text { gerenciais }\end{array}$ & $\begin{array}{l}\text { Para trabalhar com Trade Marketing é } \\
\text { essencial ter trabalhado com Vendas e ter } \\
\text { um bom relacionamento. Além disso, é } \\
\text { necessário saber motivar as pessoas a } \\
\text { fazerem aquilo que não é de } \\
\text { responsabilidade delas. Ter "jogo de } \\
\text { cintura" e conhecer muita gente também foi } \\
\text { considerado importante. }\end{array}$ & $\begin{array}{l}\text { Precisa ter passado pelas lojas, pois precisam de } \\
\text { conhecimento em relação à depósitos e layouts, } \\
\text { por exemplo. O gestor precisa também possuir } \\
\text { nível superior e relacionamento com várias } \\
\text { pessoas como diretoria e fornecedores. }\end{array}$ \\
\hline $\begin{array}{l}\text { Sistemas de } \\
\text { informação }\end{array}$ & $\begin{array}{l}\text { Existe um sistema geral, mas também existe } \\
\text { um que é apenas do Trade Marketing com a } \\
\text { utilização de indicadores específicos. }\end{array}$ & $\begin{array}{l}\text { Possuem um ERP e todas as informações são de } \\
\text { Vendas. Muitas informações acabam recebendo } \\
\text { de grandes fornecedores que fazem estudos de } \\
\text { mercado. }\end{array}$ \\
\hline Precificação & $\begin{array}{l}\text { A precificação ocorre com a área comercial } \\
\text { juntamente com o Trade Marketing. No } \\
\text { entanto, a área Comercial tem muito mais } \\
\text { influência do que o último. É muito mais } \\
\text { função da área comercial. }\end{array}$ & $\begin{array}{l}\text { A precificação é feita pela área Comercial e não } \\
\text { pelo Trade Marketing. No entanto, de acordo } \\
\text { com o entrevistado, o Trade Marketing é um } \\
\text { centro de inteligência pois analisa o que } \\
\text { aconteceu e propõe melhorias. }\end{array}$ \\
\hline
\end{tabular}




\begin{tabular}{|c|c|c|}
\hline $\begin{array}{l}\text { Calendários de } \\
\text { atividades } \\
\text { promocionais }\end{array}$ & $\begin{array}{l}\text { A área de Trade Marketing possui um } \\
\text { calendário, mas não é desenvolvido por } \\
\text { eles. }\end{array}$ & $\begin{array}{l}\text { Possuem o calendário de atividades } \\
\text { promocionais e é desenvolvido pelo Trade } \\
\text { Marketing. }\end{array}$ \\
\hline $\begin{array}{l}\text { Materiais de } \\
\text { Merchandising }\end{array}$ & $\begin{array}{l}\text { São os materiais de folheteria que são } \\
\text { comprados pelos gerentes de Trade } \\
\text { Marketing. }\end{array}$ & $\begin{array}{l}\text { São os materiais de Marketing institucional } \\
\text { como os tabloides de ofertas. Possuem também } \\
\text { degustação e amostras nos pontos de vendas. }\end{array}$ \\
\hline $\begin{array}{l}\text { Principais } \\
\text { funções } \\
\text { do Trade } \\
\text { Marketing }\end{array}$ & $\begin{array}{l}\text { É o conjunto de atividades realizadas pela } \\
\text { divisão anteriormente citada: eventos } \\
\text { (preparação de eventos, locação de vans, } \\
\text { reservas), área VIP (responsável pela área } \\
\text { premium como chopp e outras marcas } \\
\text { selecionadas) e execução (colocação de } \\
\text { materiais nos pontos de venda, execução } \\
\text { com equipamentos como chopeira e } \\
\text { geladeiras). A área de execução é a que } \\
\text { mais possui atividades. }\end{array}$ & $\begin{array}{l}\text { Análise de informações para aplicações no } \\
\text { ponto de venda, sejam elas resultados ou novas } \\
\text { ideias. Fazem definição de layouts de lojas com } \\
\text { definições de pontos quentes e pontos frios, } \\
\text { definição de cronogramas, traçam perfis dos } \\
\text { clientes e fazem a alocação dos departamentos } \\
\text { do mercado como localização de padaria e } \\
\text { açougue. Além disso, possuem relacionamento } \\
\text { com grandes fornecedores. }\end{array}$ \\
\hline Orçamento & $\begin{array}{l}\text { Quem possui o orçamento é o gerente } \\
\text { regional. O gerente de Trade Marketing } \\
\text { possui um valor para a realização de } \\
\text { atividades com a equipe. }\end{array}$ & $\begin{array}{l}\text { Não possuem um orçamento, mas o entrevistado } \\
\text { afirma que existe a necessidade de um } \\
\text { orçamento sim. }\end{array}$ \\
\hline $\begin{array}{l}\text { Dificuldades do } \\
\text { Trade } \\
\text { Marketing }\end{array}$ & $\begin{array}{l}\text { Motivar as pessoas a fazerem aquilo que } \\
\text { não é responsabilidades delas. }\end{array}$ & $\begin{array}{l}\text { A principal delas é "saber ser frio", pois algumas } \\
\text { vezes ele analisa de uma maneira com } \\
\text { informações e dados do mercado e os } \\
\text { compradores e diretoria veem de outro. }\end{array}$ \\
\hline $\begin{array}{l}\text { Conflitos entre } \\
\text { departamentos }\end{array}$ & $\begin{array}{l}\text { Não existe conflito entre Marketing e Trade } \\
\text { Marketing por não possuir divisão entre } \\
\text { elas. A divisão Trade Marketing e Vendas } \\
\text { existe e acaba acontecendo um conflito } \\
\text { quanto às funções. }\end{array}$ & $\begin{array}{l}\text { O principal conflito é a questão do "saber ser } \\
\text { frio". Além de ser uma dificuldade, ela é um } \\
\text { conflito pois acaba existindo divergências de } \\
\text { interesse entre os departamentos. }\end{array}$ \\
\hline $\begin{array}{l}\text { Oportunismo do } \\
\text { fornecedor }\end{array}$ & 20 & Não existe. Não é mais o formato \\
\hline
\end{tabular}

Fonte: dados da pesquisa.

A partir dos resultados verificamos que o departamento de Trade Marketing na empresa de bebidas foi criado para dar suporte para a área de vendas, enquanto que na rede varejista ele foi criado para ter um sortimento adequado e uma melhor dedicação da empresa. Além disso, o varejista criou o departamento para poder ter uma outra forma de relacionamento com o varejista e para verificar o que o mercado está trabalhando.

A estrutura do departamento entre as duas empresas são diferentes, afinal, elas são de portes diferentes e isso interfere na quantidade de funcionários e recursos. A primeira possui três grandes subdivisões, uma para cada função do Trade Marketing exercidas naquela empresa, enquanto que a segunda é formada por apenas quatro funcionários (um gerente, um coordenador e dois assistentes).

Quanto aos treinamentos desenvolvidos pelas empresas, verificamos que na primeira eles são mais regrados e constantes, enquanto que no varejista eles ocorrem quanto há realocação de novos funcionários ou algum tipo de ferramenta ou novidade que até então não eram utilizados.

As habilidades gerenciais necessárias para o executivo de Trade Marketing são diferentes em ambas. Na empresa de bebidas é necessário promover a motivação de uma outra equipe, e ter um bom relacionamento, além de possuir conhecimento técnico da área de Vendas. Na segunda empresa, o entrevistado apresentou alguns requisitos mais pontuais como escolaridade e relacionamento. Essa situação pode ocorrer também pelo fato da diferença de tamanho e estrutura entre elas.

A primeira empresa possui um sistema de informação específico para o Trade Marketing com o uso de indicadores que são específicos, já a rede varejista utiliza o sistema do supermercado que é baseado em vendas.

A precificação apresentou semelhanças entre as duas empresas. Em ambas ela é realizada pelo departamento Comercial, mas pode sofrer algum tipo de influência pelo Trade Marketing. 
Em contrapartida, o desenvolvimento do calendário de atividades promocionais apresentou completa divergência. Na primeira eles não são desenvolvidos pelo departamento, eles já vêm prontos do Marketing para serem executados pelo Trade Marketing. Na segunda empresa eles são desenvolvidos pelo departamento em análise. Isso pode ocorrer pelo fato de a empresa de bebidas possuir um departamento especializado para isso, enquanto que na segunda não.

As principais funções do departamento de Trade Marketing não são completamente distintas, afinal são ações realizadas no ponto de venda para que as vendas aumentem. Vale ressaltar que existem diferenças quanto a estrutura do departamento e as principais atividades realizadas, no entanto, a ideia e a intenção são a mesma.

Os orçamentos para os departamentos em ambas as empresas não são específicos. Na primeira existe um orçamento para o gerente regional e ele distribui para os gerentes de Trade Marketing realizarem atividades com suas equipes, enquanto que na rede varejista esse orçamento não existe, porém existe a consciência da necessidade.

Da mesma forma que as habilidades gerenciais, as principais dificuldades do Trade Marketing no departamento da empresa de bebidas aparecem devido a gestão entre os departamentos, enquanto que na rede varejista a dificuldade é definida com situações pontuais. Essa diferença pode ser devido ao tamanho e estrutura das empresas.

Quanto aos conflitos, foi apresentado pela rede de supermercado a mesma situação da principal dificuldade, ou seja, a dificuldade vira um conflito entre os departamentos. Já a empresa de bebidas afirma que não existem conflitos entre os departamentos de Marketing e Trade Marketing por não possuir divisão entre elas. Algumas vezes o que acaba acontecendo nessa última empresa é que aparecem conflitos entre Vendas e Trade Marketing. Quando o entrevistado afirma que não existe separação entre Marketing e Trade Marketing, ele está se referindo ao departamento que, supostamente, realiza atividades estratégicas. Afirma que isso quem faz é o Trade Marketing.

Terminado de expor os resultados obtidos nas entrevistas, eles serão analisados no tópico a seguir mediante teoria utilizada no referencial teórico desse trabalho.

\section{DISCUSSÃO}

Nesse trabalho, atendendo a questão de pesquisa, analisamos a função e operação do Trade Marketing. Tratando-se de um estudo qualitativo por meio de estudo caso, foi verificada a literatura existente e posteriormente, realizada entrevistas com os principais profissionais envolvidos. Para tanto, foram verificadas as funções do departamento de uma empresa multinacionais no setor de bebidas na cidade de Ribeirão Preto e do varejo supermercadista. Da análise de conteúdo, verificamos especificamente o atual cenário do objeto de pesquisa e por conseguinte, realizamos comparação com a teoria apresentada.

Segundo, apuramos na literatura (Alvarez, 2008) afirma que os principais objetivos do departamento são: promover atratividade no ponto de venda; garantir a visibilidade da estratégia de Marketing da empresa; apoiar e orientar os novos lançamentos de Marketing; apoiar e orientar as forças de Vendas, desenvolvendo o potencial dos clientes; desenvolver relacionamento de longo prazo com os clientes; estabelecer objetivos de presença, giro e rentabilidade por cliente e por canal; e acompanhar os custos de servir os clientes e os canais. Essas funções foram encontradas na empresa (com algumas divergências) em análise mediante as entrevistas com os gerentes de Trade Marketing e de Vendas. Eles afirmaram que a principal função do departamento (também apresentada pela teoria) é apoiar a equipe de vendas. Para isso, eles têm a função de execução no ponto de venda e fazem uso dos materiais desenvolvidos pelo Marketing. Quanto a visibilidade estratégica, ela aparece mais no departamento de Trade Marketing do varejista que acaba negociando com os fornecedores o local onde o produto será exposto. Os lançamentos de Marketing da rede supermercadista são orientados pela área de Trade Marketing, afinal, é ele que faz a divulgação e exposição desses produtos no ponto de venda.

Quanto ao relacionamento de longo prazo com clientes, o gerente de Vendas da empresa em análise, afirma que isso não é função do Trade Marketing, mas sim de Vendas. Sobre os canais, o gerente de Trade Marketing da empresa de bebidas afirma que a mensuração dos canais que eles atuam é feito por eles, mas a precificação é realizada pela área comercial, e em alguns casos, ele pode opinar. 
Além disso, (Serralvo, Motta \& Santos (2008) afirmam que o departamento está envolvido com o processo de compra do consumidor no ponto de venda e dessa forma ele pode ser entendido como o planejamento e o controle das ações no ponto de venda por meio da verificação das relações de vendas estabelecidas com o varejista. De acordo com a entrevista com o gerente de Vendas, ele afirma que é de responsabilidade do Trade Marketing realizar a execução do material no ponto de venda, fazer o consumidor ter percepção de preço e de marca e aplicar tudo o que o Marketing traz. Dessa análise, verifica-se a existência de uma certa, mas não total divergência entre a prática e a teoria.

Quanto as principais funções do departamento de Trade Marketing na empresa de bebidas estudada, podemos citar: proporcionar suporte para a área de Vendas; execução de equipamentos como geladeiras, chopeiras e post mix; execução de eventos; fazer com que o material de Merchandising chegue até o varejista; execução dos calendários promocionais.

Verificadas as funções do departamento em geral, esse trabalho permitiu comparar os departamentos de Trade Marketing da empresa de bebidas em análise e da rede varejista. As funções são em partes diferentes, mas a parte central, que são ações no ponto de venda, são iguais. Em primeiro lugar, verificamos uma diferença que pode fazer com que algumas funções acabem por ter finalidades divergentes. Essa situação é o fato de que a empresa de bebida comercializa com grandes, médios e pequenos varejistas seus produtos e portanto, tentam fazer com que eles realizem suas ações no ponto de venda. No caso dos varejistas, eles negociam com os grandes fornecedores diversos produtos para que sejam vendidos em seus supermercados. Sendo assim, o departamento de Trade Marketing da primeira empresa realiza ações para seus produtos serem vendidos em outros membros do canal e a segunda, negocia esses produtos para serem vendidos em suas lojas. Inclusive, uma das funções do departamento de Trade Marketing da empresa varejista é justamente essa, servir de relacionamento entre o mesmo departamento dos fornecedores.

Quando feita a análise das funções de Trade Marketing da rede de supermercados verificamos que as atividades desenvolvidas são de gerenciamento de categoria. $\mathrm{O}$ fato deles chamarem essas atividades de Trade Marketing pode causar uma certa confusão, principalmente porque quando se pensa no departamento, ele está relacionado com canal, o que não acontece com a situação desse trabalho. As atividades estão relacionadas as suas lojas e não a outros membros do canal.

Quanto ao relacionamento entre fornecedor e varejista, observamos que atualmente e de acordo com opinião dos varejistas, não existe mais oportunismo por parte das grandes empresas. Como dito por um dos compradores entrevistados, "não é mais o formato". Inclusive, em uma outra entrevista da rede varejista, foi dito que eles possuem informações dos fabricantes pelo fato de possuírem bastante conhecimento de mercado. As empresas precisam trabalhar juntas para que consigam chegar nos resultados almejados. Essa situação vai exatamente de encontro com a teoria apresentada por (Chung, 2012) quando ele afirma que os varejistas são dependentes dos fabricantes devido ao conhecimento de mercado. Outro fator que pode contribuir para essa inexistência de oportunismo pode ser devido ao porte da rede varejista que foi analisada, afinal, conforme dito por (Rosenbloom, 2002) o tamanho do varejista interfere no poder que é exercido. Ele pode inclusive realizar algum tipo de influência com os outros membros do canal, situação essa que não se aplica ao caso em análise.

Quanto ao perfil e funções do departamento em análise, percebe-se novamente uma divergência com a teoria. Essa situação pode ser percebida quando (Alvarez, 2008) afirma que o departamento de Trade Marketing foi desenvolvido com a intenção de apoiar e dar suporte a área de Marketing e Vendas, no entanto, quando analisada a entrevista com o gestor de Trade Marketing da empresa de bebidas, o departamento em análise é apresentado como um auxílio e suporte para a área de Vendas e que foi criado para isso, dar suporte à área comercial e não para a área de Marketing como apresentou o autor. Ele afirma também que as funções são bem separadas e que não há congruência entre elas. Assim e como apresentado anteriormente a área de Trade Marketing não é um departamento do Marketing, mas sim da parte comercial e por fim, afirmam também que o comercial não possui grande influência na parte estratégica, mas sim na parte de criação e inovação.

Seria relevante propor um esquema para a empresa em análise que pudesse representar de forma teórica aquilo que foi visto na prática. Podemos perceber por meio dos resultados coletados com as entrevistas, que o departamento de Trade Marketing é utilizado na empresa como forma de apoio ao departamento de Vendas, sendo assim, juntos eles formam a parte comercial da empresa. Quanto ao departamento de Marketing, ele é responsável pela parte de criação e inovação da empresa e não possui grande interferência nas ações do Trade Marketing. Dizer que não possuem relação seria um erro, afinal, 
o Marketing cria as campanhas e produtos que serão aplicados e utilizados pelo departamento de Trade Marketing.

A partir dessas conclusões desenhamos um esquema que se adeque mais a essa empresa. $\mathrm{O}$ esquema proposto por Cônsoli; D’Andréa (2010), mediante conclusões anteriores, não se aplica a empresa em análise. Sendo assim, propomos o esquema conforme figura 3.

Figura 3 - Esquema Trade Marketing proposto - Empresa de Bebida em análise.

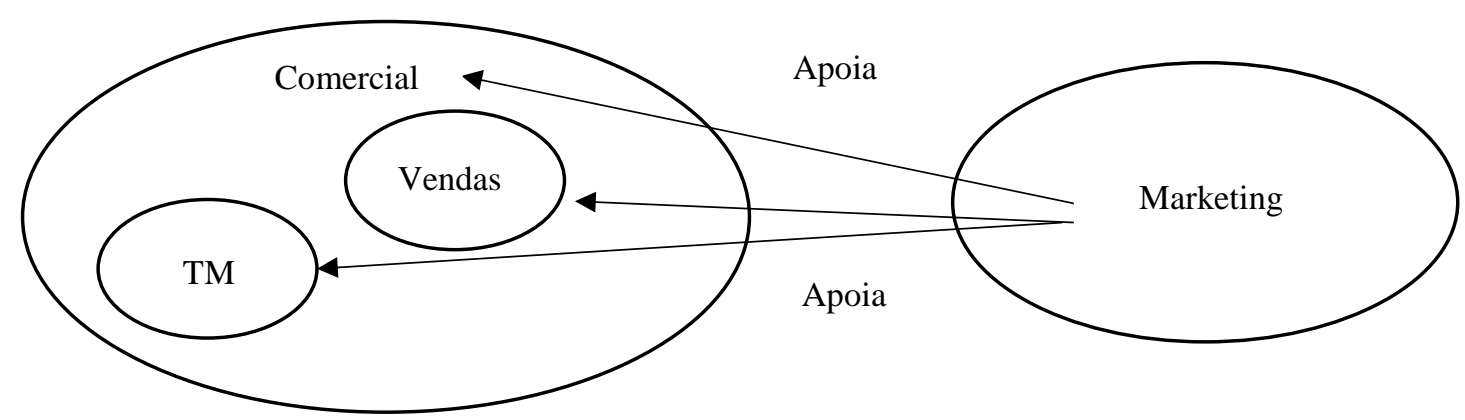

Fonte: elaborado pelos autores (2016)

Pode ser verificado a partir da figura 3 que os departamentos de Trade Marketing e Vendas estão dentro do departamento Comercial da empresa de bebidas e recebem o apoio de materiais e campanhas desenvolvidos pelo departamento de Marketing.

Vale ressaltar que o esquema anterior não se aplica a todas as empresas que possuem um departamento de Trade Marketing, afinal, cada empresa possui uma estrutura que deve ser respeitada. Essa divergência de estruturas pode ser percebida inclusive nesse trabalho quando se analisou o departamento de Trade Marketing de uma rede varejista. O departamento dela está localizado no Marketing, no entanto, está mais relacionado a parte comercial como pontos de lojas e layouts.

Em relação a estrutura do Trade Marketing na empresa de bebidas, verificamos a existência de um departamento que auxilia a área de Vendas e a partir dessa situação, questionamos a necessidade da criação de um novo departamento com um nome diferente. Visto a grande relação entre os dois departamentos, talvez não fosse necessário esse novo termo, mas sim, funcionários do departamento de Vendas que possuíssem essas funções. No entanto, deve ser levado em consideração a liberdade das empresas de criarem nomes para seus departamentos. $\mathrm{O}$ que pode ser verificado em pesquisas futuras, é se existe um departamento que esteja realizando atividades em duplicidade, ou seja, uma mesma função está sendo desempenhada por dois departamentos.

Sobre o treinamento do departamento, verificamos existirem, tanto na empresa de bebidas e na rede varejista. Na empresa de bebidas, os treinamentos são mais frequentes que na rede varejista, inclusive, parece ser repassado mais um aprendizado cotidiano do que um treinamento em si. Essa existência do preparo dos funcionários vai de encontro com (Silva Neto, 2009) que afirma que o treinamento, bem como o sistema de informação, são variáveis que contribuem com o conhecimento na área. Em relação ao sistema de informação, a empresa de bebidas possui um sistema geral, mas também possuem um próprio que é responsável por análise e fornecimento de indicadores do departamento. A rede varejista possui um ERP que possuem todas as informações baseadas em vendas.

Quanto a relevância do Trade Marketing, percebemos que os varejistas acreditam na importância do departamento quando mencionam a necessidade de uma área que faça a ligação entre supermercado e fornecedores. Além disso, afirmam que é esse departamento que faz a parte estratégica de alocação de produtos e prateleiras, o que pode permitir que aumente a quantidade de vendas.

Da análise da função e operação do profissional de Trade Marketing, os dados coletados levam a verificação de que o profissional desse departamento trabalha juntamente com o profissional da área de vendas para melhorar e aumentar as vendas da empresa, para tanto utiliza de atividades desenvolvidas pelos departamento de Marketing e Merchandising para serem aplicadas nos pontos de vendas como indicado por (Cônsoli \& D`Andrea, 2010), e assim incentivarem o consumo, em consonância com levantes teóricos de (Alvarez, 2008). Além disso, o departamento possui sistemas de informação capazes de desenvolver e analisar indicadores ou informações que podem ser importantes 
para futuras ações nos pontos de vendas. Percebe-se, portanto, que também existe uma relação estratégica com o departamento, que aparece, mas não é tão imponente quanto a questão de ações nos pontos de venda.

Das análises inerentes ao perfil da estrutura do departamento do Trade Marketing, verificamos que esse departamento existe em conjunto com o da área comercial desde o início, tendo sido criado com a intensão de auxiliar e aumentar vendas da empresa. Assim como nos estudos de (Randall, 1994), a adequação na estrutura também se deu pela necessidade de ajustar ao ambiente de negócios e, das entrevistas levantadas, tal procedimento fica bem evidenciado, principalmente nas especificidades desse estudo. A estrutura funcional é formada pelo vice-presidente que ocupa o cargo mais alto dessa área, abaixo dele na estrutura hierárquica existe um gerente regional, no caso o entrevistado, é o gerente da regional Paraná-Interior. Em seguida, os gerentes de marketing execução que possuem três segmentos: execução (realizam a parte de execução nos pontos de venda), VIP (são responsáveis pelos clientes premiuns e por algumas bebidas mais selecionadas como chopp) e connections (refere-se aos funcionários que tem a reponsabilidade dos eventos). Os profissionais de hierarquia mais baixa são os supervisores.

Em outra análise buscamos verificar as principais funções dos profissionais no Trade Marketing na empresa estudada, sendo verificado que as principais funções desses profissionais (gerentes de marketing execução) são as relacionadas aos segmentos apresentados anteriormente. A primeira divisão, a parte de execução é responsável pelos materiais de folheteria, pelos equipamentos de refrigeração, verificar se tem material de Merchandising para a execução do preço até o ponto de vendas. A segunda divisão é VIP. Os profissionais responsáveis pelas marcas premium de bebidas e são responsáveis e por fim a terceira divisão do gerente de marketing execução é o connection. Ela é relacionada a eventos desenvolvidos pela empresa.

No processo de investigação também buscou analisara relação entre os departamentos de Trade Marketing, Marketing, Merchandising e Vendas conforme também apontado nos estudos de (Alvarez, 2008). Das entrevistas, verificamos que o departamento de Marketing desenvolve as campanhas utilizadas pelo Trade Marketing, o Merchandising faz os materiais que promovem a venda e o departamento de Vendas, vende. Verificamos também que o departamento não existe com o mesmo nome que em outras empresas, fazendo parte de um departamento maior, como é o caso da empresa em análise que não possui separação entre Marketing e Merchandising.

Quanto as questões inerentes ao relacionamento entre os membros do canal, assim como no estudo de (Serralvo, Motta \& Santos, 2008), quando enfatizam que a mais importante característica do Trade Marketing reside na criação de um relacionamento entre fornecedor e cliente, no presente estudo verificamos ser considerado bom, inexistindo o oportunismo e poder do maior em relação ao menor, e sim, sinergia para alcançarem um objetivo comum. Em relação ao varejista, o departamento de Trade Marketing aparece na mesma circunstância, dado que, é responsável por manter relação com os grandes fornecedores. Cabe destacar que nesse caso do varejista, adaptou o departamento de uma maneira inversa à maneira de ação do fornecedor/distribuidor. O negócio começa na parte estratégica com os compradores e termina com o Trade Marketing.

Uma última preocupação no estudo foi verificar as considerações dos varejistas em relação ao departamento em análise. Verificamos que esses acreditam na importância do departamento, principalmente pelo elo para com os fornecedores. Além disso, destacam a importância do departamento quanto a execução no ponto de venda. Tal verificação vão ao encontro de estudos citados no decorrer do presente trabalho (Da Costa 2004; Arbache, 2006; Silva Neto, 2009; Alvarez, 2008; Serralvo, Motta \& Santos, 2008). Para tanto utiliza de atividades desenvolvidas pelo departamento de Marketing e Merchandising para serem aplicadas nos pontos de vendas e incentivarem o consumo. Além disso, o departamento possui sistemas de informação capazes de desenvolver e analisar indicadores ou informações que podem ser importantes para futuras ações nos pontos de vendas (Almeida, 2012). Percebe-se, portanto, que também existe uma relação estratégica com o departamento, que aparece, mas não é tão imponente quanto a questão de ações nos pontos de venda.

As discussões aqui inseridas, colaboram para análise e aprofundamento teórico, pois, além de confirmar indicativos teóricos já existentes, apresentou adaptação de função em relação ao departamento de Trade Marketing. Essa constatação é importante, pois, cabe em trabalho futuro verificar se o mesmo ocorre em outros setores. Abre oportunidade de pensar no modo como as redes varejistas menores tem se estruturado para enfrentamento do comportamento oportunista do fornecedor. 
No desenvolvimento desse estudo, existiram algumas limitações que serão aqui explicitadas para facilitar pesquisas futuras. Além disso, serão dadas algumas sugestões que poderão melhorar estudos que estão por vir.

A principal limitação, foi a pouca teoria acerca do tema em análise. Mesmo em busca ampla verifica-se ainda oportunidades de exploração do tema em pesquisas futuras as quais podem nortear e enrijecer a literatura. Outra limitação, foi em relação a amostra adotada no presente estudo de caso, pois, muito embora pese considerar a empresa estudada ser multinacional de amplo acesso ao mercado, o caso foi único e se concentrou em uma única região do Estado de São Paulo. Para futuras pesquisas, poder-se-á desenvolver estudos de caso múltiplos e com outras empresas ou até mesmo fazer uma comparação entre elas. Além disso, realizar estudos em outros setores também seria conveniente, podendo confirmar um modo de atuação ou até mesmo a propor um modelo para o setor.

Uma outra indicação para futuras pesquisas seria o estudo do departamento de Trade Marketing sob o ponto de vista de outro departamento da empresa, dessa maneira e numa análise da estrutura organizacional verificaria a real importância do departamento.

As discussões aqui apresentadas revelam o cenário estudado em relação a atividade do Trade Marketing para empresas envolvidas no canal de distribuição em sua totalidade. Cabe destacar a importância que esse departamento passa a obter já que, consegue desenvolver e melhorar o relacionamento no canal gerando benefícios aos envolvidos. Tais verificações revelam a importância do tema, seja para academia seja para as empresas.

\section{CONCLUSÃO}

As contribuições do presente estudo, demostram que o tema embora considerado recente no Brasil, ainda aparece mais na prática do que na teoria, não significando que as atividades realizadas pelo departamento sejam novas, o que pode estar ocorrendo é a realocação delas para esse novo departamento, o Trade Marketing.

A principal contribuição do trabalho foi poder verificar que muito do que é previsto na teoria acontece na prática empresarial, podemos dizer muito, mas não em sua totalidade, pois, contatou-se que existe uma certa, mas não total divergência entre a prática e a teoria. $O$ departamento de Trade Marketing na empresa de bebidas foi criado para dar suporte para a área de vendas, enquanto que na rede varejista ele foi criado para obtenção de um sortimento mais adequado e uma melhor dedicação da empresa, além de buscar melhorar a forma de relacionamento com o distribuidor e ainda, melhorar capacidade de análise de mercado. Muito embora, algumas funções possam deferir no departamento de Trade Marketing entre as empresas, quando de ações no ponto de venda, são iguais. No presente caso, em específico, também foi constatado que o relacionamento entre distribuidor e varejista já não é mais guiado por oportunismo e poder.

Em relação à congruência das funções dos departamentos de Marketing, Vendas, e Trade Marketing, na empresa em análise isso não existe. O primeiro cria e desenvolve produtos, o segundo vai em busca de vender e o terceiro realiza atividades que fazem com que as vendas da empresa melhorem. Vale ressaltar que o Trade Marketing é um departamento que utiliza de algumas ações no ponto de venda para aumentar as vendas da empresa, ações verificadas em ambas empresas.

Por fim, verificou-se que as empresas possuem a liberdade de chamarem seus departamentos do nome que desejarem, muito embora, exerçam praticamente as mesmas funções, isso pode causar certa confusão principalmente quanto as funções e atividades desenvolvidas pelos funcionários desses departamentos. Chamar um departamento de Trade Marketing subentende-se que tal departamento irá realizar atividades que foram descritas conforme apontadas pelos pesquisadores na área. No entanto, o processo de adaptação estrutural das empresas quando de nomeação de seus departamentos, parece ainda indefinido. 


\section{REFERÊNCIAS}

ALMEIDA, V. M. C.; SIANO, P. L.; FREITAS, G. F.; D’ALGERBAGARIA, F. (2012). Trade marketing no setor de lojas de conveniência. Rev. Adm. Empresas, São Paulo, 52(6).

ALVAREZ, F. J. S. M. (2008). Trade Marketing: a Conquista do Consumidor no Ponto de Venda. São Paulo: Saraiva.

ARBACHE, F. S.; SANTOS, A.G.; MONTENEGRO, A. G.; SALLES \& CHRISTOPHE, FERREIRA, W. Gestão de Logística, distribuição e trade marketing. Rio de Janeiro, FGV Editora.

ASSOCIAÇÃO BRASILEIRA DE ANUNCIANTES. Glossário de Promoção e Merchandizing. Brasil (2016, 28 de setembro). Recuperado de http://www.aba.com.br/canais/trade-e-shopper-marketing/documentos/glossario-de-termosusados-em-promocao-e-trade-marketing.

ASSOCIAÇÃO DOS FABRICANTES DE REFRIGERANTES DO BRASIL (AFREBRAS): Brasil. (2016, 30 de setembro). Recuperado de www.afrebras.org.br.

BARDIN. L. (2011). Análise de conteúdo. São Paulo: Edições 70.

BARROS, T. F. (2015). As atividades do Trade Marketing aplicadas no setor farmacêutico. São Paulo. 2015. (Dissertação de Mestrado) - Universidade de São Paulo - USP, São Paulo, SP, Brasil. Recuperado em http://www.teses.usp.br/teses/disponiveis/12/12139/tde19012016-152801/pt-br.php

BLESSA, R. (2012). Merchandising no Ponto-de-venda. 5a . ed. São Paulo: Atlas.

CHUNG, J. (2012). When and how does supplier opportunism matter for small retailers' channel relationships with the suppliers. Journal of Business Management.

CÔNSOLI, M. A.; D’ANDREA, R. (2010). Trade Marketing - Uma estratégia de distribuição e execução de vendas. São Paulo:

Atlas.

COUGHLAN, A. T.; ANDERSON, E.; STERN, L. W.; EL-ANSARY, A. L. (2011). Canais de Marketing. $7^{a}$ edição. São Paulo. Pearson.

DA COSTA, F. J.; LEOCADIO, A. L.; LEOCÁDIO, A. L.; ARAÚJO, M. A. T. (2004, 3 a 5 de novembro). Trade marketing na relação produtor-varejista: um Trade marketing na relação produtor-varejista: um estudo exploratório no setor avícola cearense In: XXIV ENCONTRO NAC. DE ENG. DE PRODUÇÃO - Anais Semead. Florianópolis, SC, Brasil, Recuperado em <http://www.abepro.org.br/biblioteca/ENEGEP2004_Enegep0111_1611.pdf

DEWSNAP, B.; JOBBER, D. (2009). An exploratory study of sales-marketing integrative devices. European Journal of Marketing, 43(7/8), pp. 985-1007.

DUPUIS, M.; TISSIER-DESBORDES, E. (1994) Trade Marketing: mode ou nouvelle approche des relations producteurs/distributeurs? DécisionsMarketing, (2), pp 45-57. 
DUPUIS, M.; TISSIER-DESBORDES, E. (1996) Trade Marketing and Retailing: a European approach. Journal of Retailing and Consumer Services, (3), pp. 43-51.

KOTLER, P.; KELLER, K. L. (2012). Administração de marketing. $14^{\circ}$ ed. São Paulo: Pearson Prentice Hall.

MENTZER, J.; MIN, S.; ZACHARIA, Z. (2000). The nature of interfirm partnering in supply chain management. Journal of Retailing. 76(4), pp. 549-568.

RANDALL, G. (1994). Trade Marketing Strategies: the partnership between manufactures, brands and retailers. $2^{\mathrm{a}}$ edição. Oxford: Butterworth-Heinemann.

ROSEMBLOOM, B. (2002) Canais de marketing uma visão gerencial. São Paulo: Atlas.

SERRALVO, F.; MOTTA, R.; SANTOS, N. (2008). Trade marketing: Teoria e prática para gerenciar os canais de distribuição. Rio de Janeiro. Elsevier.

SILVA NETO,N. B. (2009). Assegurando adequação estratégica do trade marketing Foco em empresas de bens de consumo. Rio de Janeiro. 2009. (Dissertação de Mestrado em Administração de Empresas) - Pontíficia Universidade Católica do Rio de Janeiro, RJ, Brasil. Recuperado de http://www.dominiopublico.gov.br/pesquisa/DetalheObraForm.do?select action=\&co_obra= 153091.

YIN, R. K. (2010). Estudo de caso: Planejamento e Métodos. $5^{\mathrm{a}}$ edição. São Paulo. Bookman.

\section{COMO CITAR (APA):}

Deliberali, R., Mendonça, P., \& Nascimento, C. (2017). Análise da função do Trade Marketing: estudo de caso em uma empresa multinacional de bebidas na cidade de Ribeirão Preto - SP. Intern. Journal of Profess. Bus. Review, 2(1), 58-71. http://dx.doi.org/10.26668/businessreview/2017.v2i1.42 